\title{
Enhancing the Quality of Teaching to the Students through Reading
}

\author{
PhD Candidate: Albana Tahiri
}

Ministry of Educations and Sport, Tirana

\section{Doi:10.5901/ajis.2014.v3n1p295}

\section{Abstract}

Problems of quality of learning students, allover in the field of education have become the issue of the day. Referring to the research and evaluation on national and international levels, it is noticed that the quality of learning among students has been declining. Albanian schools despite the changes and reforms undertaken in recent years have faced a lower quality of students at various educational levels. Issues on functional illiteracy highlighted in a study performed by the World Bank (WB "Overview of the partnership program" June 2013), but also through the PISA assessments and evaluations at the national level have evidenced issues related to the quality of student learning process. One of the core issues related to student inability to succeed is the quality of their reading, this highly important component for success. Based on our school experiences, but as well on concrete research on this issue, we have undertaken this work through which we intend to emphasize some issues dealing with the issue of reading, in order to find some way out to improve reading in our schools. For this purpose our study work extends its scope to some specific issues related to student reading in compulsory education, considering at the same time previous research on this area of study, starting from the evaluation of programs, curricula, reading skills of students and to teachers' professional skills for teaching.

Keywords: quality of learning, the process of reading, reading assessment, strategy techniques for reading etc.

\section{Preface}

Recognizing the problems of the school in enhancing the quality of learning while understanding, thinking, and judging on this field of study, we believe that the reading process itself is the key which can change the quality of learning for students in school. Time requires new standards and parameters.

For this purpose in the Albanian school practice efforts and curricular reforms have been made, that are directly related in improving the quality of student learning process at different levels of education. These reforms have been focused primarily on improving the school curriculum, which is oriented toward the development of critical thinking, interactive teaching, and integration within and among different subjects, finding techniques and strategies that enable this kind of teaching. "Accordingly, curricular reform should address the priority of teaching and learning quality aspect..." (2004-2015 "National Strategy on Education" MES). All these innovations are accompanied by reform of alternative text which has provided a new and more diversified content regarding the implementation of the school curriculum. Such curriculum changes are assessed as positive, but with the passing of time they have pointed out many issues which are part of our research "Changes were noted while changing the direction from linear programs to integrated and combined programs, which brought a different perspective on Albanian language program. (Gjokuta, 1994)

In Albania, teaching in the pre-university education, after the period 1990-2014 has been associated with significant changes, which have affected the content aspect of the subjects and the process and methodology of teaching and learning. These changes have made strong didactic innovation, giving to the learning process a new perspective both in the curriculum's content and in the process of teaching and learning.

A broad contribution and support to curricular reform has been given from some international organizations, who have monitored and made possible the implementation of many projects related to the improvement of educational content such as: (World Bank 2003 - ongoing ) which gave a strong support to reform curricular, "Developing critical thinking through literacy" ( SOROS 1997-2004 ), global Education (Unicef 1994 -ongoing), "Interaction in class" (Save the Children 2004 to 2013 ) USAID, PNUD, ect.

The support of these organizations offered to the Albanian education lot of publications for students and teachers giving a new spirit consistent with global developments.

Meanwhile we must admit that although we have this strong support, the Albanian education is facing numerous problems related mainly to further improvement of its quality. 
For this purpose we have chosen one of these problematic "the issue of quality of reading" to make it as the subject and research of this study.

We hope that through this research we will contribute to the clarification of ideas and methodological solutions that give reading a better understanding, to teachers as well as to students.

\section{The Following Methodology Clarifies Our Ideas about this Research}

This study is based on a methodology which includes quantitative and qualitative aspects. Quantitative because our search is extended to a large number of students and teachers in some schools of Tirana, who have undergone several tests, measurements, surveys and questionnaires, through which we have gathered supportive data to base our findings about the reading process and integration between different subjects in the reading area.

The study was extended to four schools in Tirana, approximately to forty teachers and one thousand students. Simultaneously expansion in these schools has provided comparative values to the study that make reliable the obtained results.

In this paper we have use statistical methods, which have allowed us to come to certain conclusions about the process of reading.

Measuring the reading speed was another methodological form of data collection.

Methods of developing critical thinking have helped us to involve students in depth learning activities, through reading process. This method has dictated us to consider and evaluate in this paper the benefits that such methods have in the teaching and learning process, always when they are known and used appropriately. (Insert, network discussion, two -part diary, concept table, etc.)

\section{Issues of Quality Learning to Students through Reading}

Reading may seem the easiest thing, since many people believe that the ability to read is acquired in the beginning of their education, but there is a profound difference between reading literacy physically and mentally. To understand what you are reading is the real challenge. Understanding is an unavoidable element of the intelligence of a human being who is born with this gift. Knowledge acquired through reading enriches a person vocabulary, eloquence, and ideas creating this way a stable capability to speak. Considering reading as one of the most important components of learning, which opens up all other processes of intellectual development of the individual, we must admit that the teacher of the Albanian language and literature should focus more on this component of learning.

"Reading is a process that leads to seeking something, but also it is an emotional and desire need of the individual. It is a sign of human life and a process that fulfills certain personal and social purposes." (Gjokuta, 2009, page 203)

Albanian language teacher more than anyone else should study on the quality of reading and learning of students. The Albanian language teacher is the first who can make appropriate corrections to all students who have learning difficulties during reading. In no other school subject can be successful a student who can not read. Teachers of other subjects often complain about teachers who have taught initial reading and writing to students.

Through the objectives of National Education Strategy in particular is distinguished the objective empowered by law: "... will bring close the Albanian education system with that of most other Balkan countries, EU and OECD countries. The first two levels focus on literacy, mathematics, knowledge of health and society and in the acquisition of knowledge and skills in order to participate actively in a democratic society based on knowledge." (A.2 Improving the quality of teaching and learning (teaching/learning) National Education Strategy 2004-2015, www.mash.gov.al)

To illustrate the above idea, in this paper we will provide a modest research conducted in some schools of Tirana on the quality of students ' reading and will make some comments about the findings of this research.

In order to test the quality of reading, was first drawn a test, then a questionnaire that was implemented in about 1000 pupils, including grades 2-9 of the compulsory education.

The following data highlights specific information about the quality of reading in different grades of the nine-year compulsory education.

By reading the table horizontally we can obtain some data for different components of reading. Of course these figures reflect what really happens in school. They are the unit of measurement that show reading standards.

It is not enough just to know these data, but also to interpret them. Below for this purpose we will make some interpretations based on the data of the following table. 
Table 1: Statistical data over the quality of reading

\begin{tabular}{|c|c|c|c|c|c|c|c|c|c|c|}
\hline No & Grade & $\begin{array}{c}\text { Take } \\
\text { off/Add } \\
\text { letters }\end{array}$ & $\begin{array}{c}\text { Repeated } \\
\text { Reading }\end{array}$ & $\begin{array}{c}\text { Different } \\
\text { Reading }\end{array}$ & $\begin{array}{c}\text { Total no.of } \\
\text { mistakes } \\
\text { (jo/nx) }\end{array}$ & $\begin{array}{c}\text { Words in } \\
\text { one } \\
\text { minute }\end{array}$ & $\begin{array}{c}\text { Average } \\
\text { words in } \\
\text { one minute }\end{array}$ & $\begin{array}{c}\text { Total No. Of } \\
\text { Students }\end{array}$ & $\begin{array}{c}\text { No / of } \\
\text { students who } \\
\text { read correctly }\end{array}$ & $\begin{array}{c}\% \text { Of } \\
\text { accuracy }\end{array}$ \\
\hline 1 & II & 36 & 20 & 24 & 80 & 7130 & 78 & 90 & 51 & 56.7 \\
\hline 2 & III & 64 & 52 & 24 & 140 & 7375 & 77 & 95 & 53 & 55.7 \\
\hline 3 & IV & 15 & 46 & 79 & 140 & 8835 & 99 & 87 & 51 & 58.5 \\
\hline 4 & $\mathrm{~V}$ & 59 & 63 & 63 & 185 & 6815 & 81 & 85 & 33 & 39 \\
\hline 5 & $\mathrm{VI}$ & 68 & 71 & 68 & 227 & 7304 & 88 & 98 & 34 & 34.6 \\
\hline 6 & $\mathrm{VII}$ & 89 & 76 & 81 & 246 & 13399 & 131 & 102 & 38 & 37.2 \\
\hline 7 & $\mathrm{VIII}$ & 118 & 110 & 86 & 314 & 21562 & 147 & 146 & 46 & 38.9 \\
\hline 8 & $\mathrm{IX}$ & 88 & 83 & 44 & 215 & 22353 & 180 & 124 & 60 & 48.3 \\
\hline 9 & $\mathrm{II}-\mathrm{IX}$ & 437 & 521 & 479 & 1437 & 94723 & 114 & 827 & 376 & 45.5 \\
\hline
\end{tabular}

Statistics of this study show very desperate data in relation to the language skills of students, data who are not very optimistic. Significant weaknesses are evidenced in their overall linguistic formation, disabilities in reading and enhancing of spoken and written language.

The average reading speed read per minute for students from second grade to sixth grade is below 100 . Within this interval weakness are evident to students of the fifth class where the same indicator was significantly lower (81 words per minute) compared with indicator of fourth grade students who read on average 99 words per minute.

Analysis as per each grade shows the following:

- In second grade 90 students in total: 51 students read correctly in compliance with applicable standards, the average reading speed is 78 words per minute and with 56.7 percent accuracy.

- In third grade with 95 students in total: 53 students read correctly per applicable standards, the average reading is 95 words / min and the accuracy is $55.7 \%$.

- In fourth grade 87 students in total: 51 students read correctly as per applicable standards, the average reading speed is 87 words / min and with $58.5 \%$ accuracy.

- In the fifth grade 85 students in total: 33 students read correctly as per applicable standards, the average reading speed is 81 words / min and with $39 \%$ accuracy.

- In sixth grade 98 students in total: 34 students read correctly as per applicable standards, the average reading speed is 88 words / min and with $34.6 \%$ accuracy.

- In seven grade 102 students in total: 38 students read correctly as per applicable standards, the average reading speed is 131 words / min and with $37.2 \%$ accuracy.

- In grade eight 146 students in total: 46 students read correctly as per applicable standards, the average reading speed is 147 words / min and with $38.9 \%$ accuracy.

- In grade nine 124 students in total: 60 students read correctly as per applicable standards, the average reading speed is 180 words / min and with $48.3 \%$ accuracy.

In overall it is evidenced that, the reading accuracy is very low, as well as the spelling is not correct. The transition of students from one grade to another has its own risks and affects the quality of learning. Subject overloading is a common phenomenon in Albanian language textbooks for secondary school students. As a phenomenon that accompanies school step by step, subject overloading occurs in other school texts, which, make more difficult their learning due to the language they contain. The student does not find the necessary space to work with the book if within are presented a large number of topics and overloaded materials.

There is a linguistic and psychological phenomenon we can use as a tool to explain this fact. We face significant weaknesses with students toward the correct and appropriate pronunciation of our native language, errors in reading, poor language formulation while speaking, or insufficient skills and little desire to read, not willing to work with the text book, the way how words are written and the spoken etc.

It is common that when students move from one school level to the next, the learning quality declines, the texts become more difficult and longer, teacher are more rigorous which in turn affects the students' desire to read. While the number of science subjects increases less time remains for leisure reading. Slowly, in the school curriculum, without considering the age development capabilities, there is created overload in terms of volume of texts to be read.

This happens consistently with the grade six's students and onwards. So the transition from one cycle to another affects the quality of reading. 
Certainly the quality of this data is affected by the work done from Albanian language teachers, on how much importance they place to the continuous process of reading. The conclusion is that the pupil believes that whiles moving to higher grades, he/she can read correctly, but instead it is increased the number of students who do not read accurately, a fact noticed by teachers of various subjects from six grades to nine grades, stating that the students work little with the textbook.

This analysis highlights the fact that in some indicator the reading quality falls from class to class, going from the bottom up. Other factors significantly related to this decline are the loss of time on the Internet and other electronic games, preparing assignments with data from the Internet, where students just print them and do not read them.

Students should turn crude materials from the Internet in written elaborated synopsis. In this way they would set in motion the reading and writing process etc.

\section{Data from the Teacher's Survey}

Language learning curriculum included in the curriculum reform, has undergone many changes and innovations that relate to the matter of different subjects integration in the structure of the curriculum, through lines which have given to the curriculum coherence and comparability with contemporary curriculum of learning languages.

Another element which enables the integration has been the mutual relationship between the language and the reading subjects and between educational subjects as a whole, through which has been required that learning the language should be the goal and objective of each learning subject, evident in the curricular framework and compassion in every school subject ( ISP , IKS " Framework Curriculum" 2003 )

\section{Results and Analysis of Survey}

Number of interviewees: 40 (forty) teachers. Teachers of nine-year school system in the city of Tirana, from second grades to nine grades.

\subsection{The principle of integration in your subject makes a difference for you?}

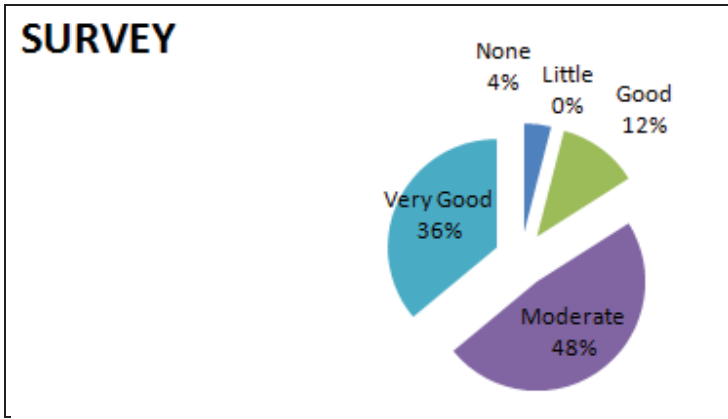

5.2 The techniques and teaching methods enable subject integration?

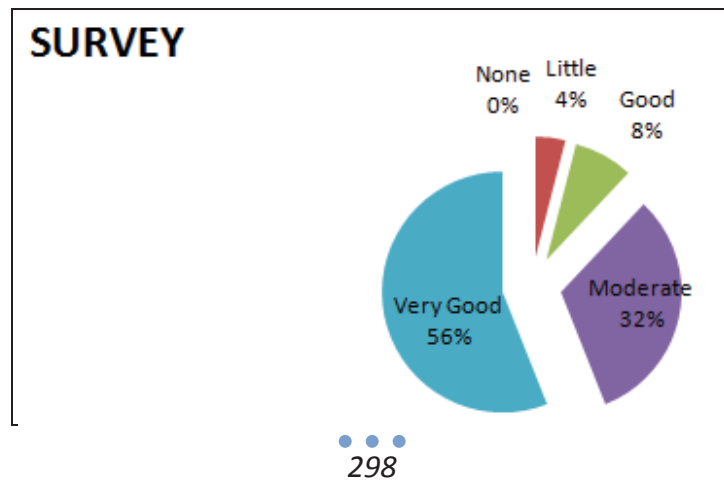


5.3 Does the learning process, with its focus on the student- enables an active and productive reading process?

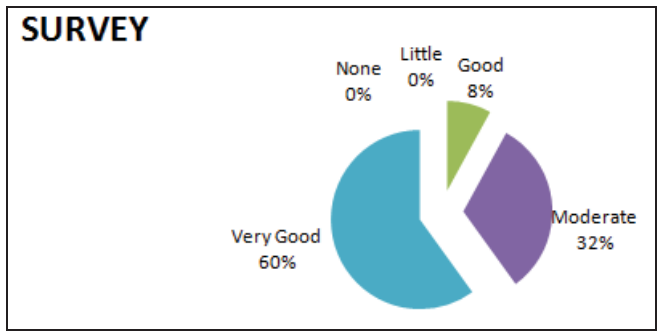

5.4 Focused reading restricts the use of different teaching methods?

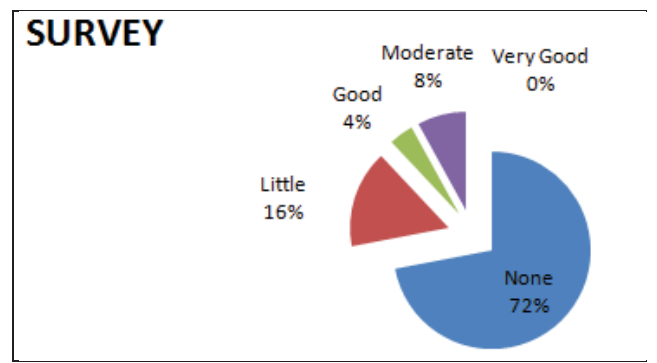

5.5 Is the Quality of reading declining passing from one grade to the other in both cycles?

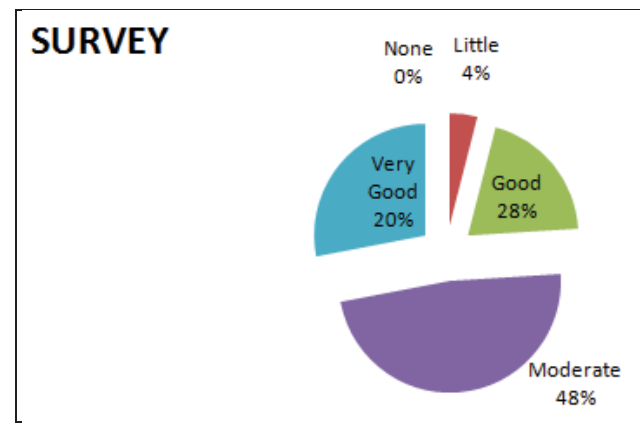

5.6 How much does the focused reading affect the consolidation of knowledge between different subjects?

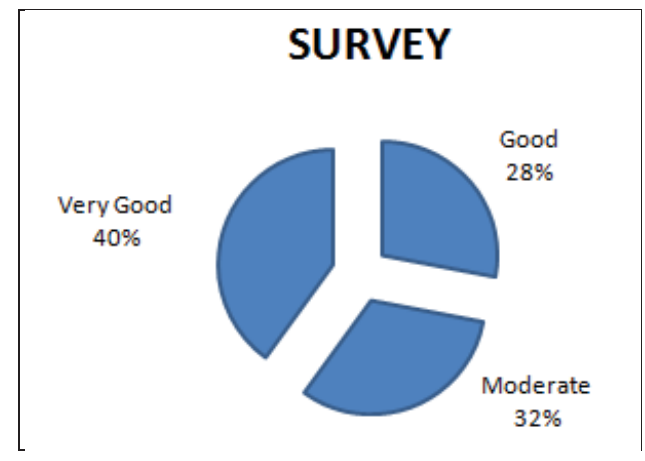


5.7 How adversely does Internet use affect the reading and writing process?

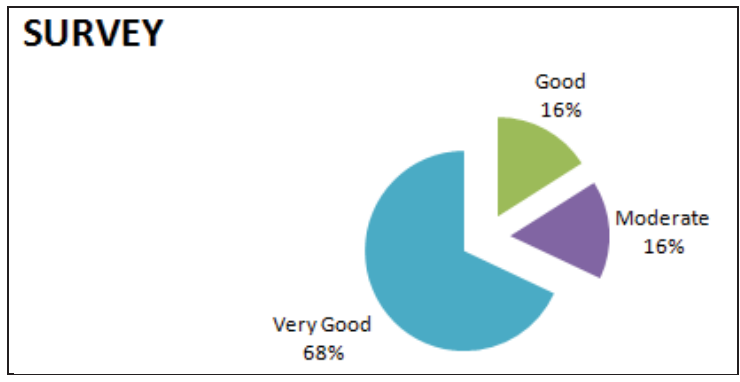

5.8 What is the percentage of teachers requiring that materials obtained from the Internet be turned in written synopsis?

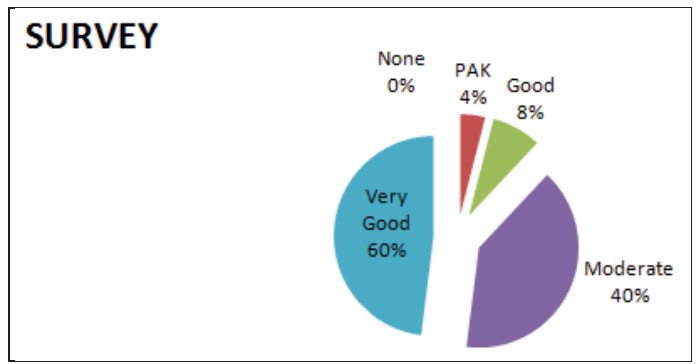

5.9 With the reading process should work only elementary teachers or teachers in both cycles?

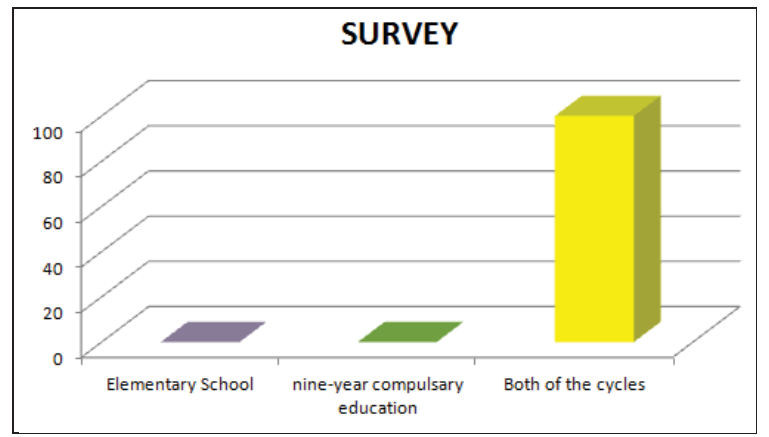

As seen from the table positive results are in favor of reading, despite the reluctance or the inability to absorb innovation and getting away from the tradition.

Teachers have welcomed the introduction of new innovations and that the principle of integration serves the best to the teaching process, thus cultivating students' active reading. Melting and extending knowledge of different subjects, that share common knowledge and that are reflected during the learning process should be used for a more concrete and scientific learning.

"To become a better teacher, it means having more confidence and assurance when deciding on issues of teaching, having at the same time commitment to improve further ... "(Fullani, 2001, page 194)

The teacher must be aware that in addition to learning contents (for example scientific knowledge) the teacher should use different voice tone, gesture , movement, etc. , that the within the field of performance of teachers we call it "warmth and enthusiasm" that the teacher uses in class.

The teacher should transform the class in learning activities and tasks " learning time should be seen differently: as 
a cake which students share in different learning activities like reading, speaking and writing. In order to succeed in this kind of teaching, the teacher should recognize the best features of each individual student about their learning styles .. " ( Gjokuta, 2009, page 266)

Application of teaching focusing to the student, subject integration, teamwork, creative and interactive ability of students, does not limit active reading to students, but rather motivates students to be more active, not as an object, but as an active subject in the learning process.

The reading process requires a lot of efforts not only in primary or nine-year school system but in both cycles. Several years' effort productivity is evident and tactile.

In both cycles the reading process is treated as a duty of all teachers in all subject profiles.

Regarding the problem of reading the Albanian language subject, the Albanian public opinion and various specialists have not remained indifferent. There have been different attitudes, among which some have been supportive and some opposing.

\section{Conclusions}

- The success and quality of learning in the case of the Albanian language requires a learning process updated with new methods, strategies and active learning techniques, interactive, comprehensive, which at the same time interact and play a decisive role in the quality of teaching process to students.

- The reading process should be seen as a comprehensive and active process not only in compulsory education, but in all levels of education. We should highlight the fact that reading should not remain just reading, but rather reading should be used for consolidation of knowledge gained from the text.

- Textbooks must be clear and understood by the students in order for them to absorb standard language. So attention must be paid to the scientific side of the textbook.

- Teachers should insist that occasionally test the knowledge acquired by students through reading, in order to increase the level of knowledge acquisition in both cycles.

- In both two cycles the reading and writing process should not be treated as a task of language teachers only, but as a task of all teachers in all subject profiles.

- The teacher should insist on reading, because students enrich the discourse on the Albanian language skills (written and oral) in all possible environments and circumstances of the communication, in the four main components: listening, speaking, reading and writing.

- The students should be aware that reading not only enriches the vocabulary, but also makes it easier integration into society where they live.

- For this purpose the study we offer has highlighted many issues that respond to the specific learning environment at school.

- These studies are insufficient if only remain at the level of study and not considered for changes and continuous improvements.

\section{References}

Fullan, M. (2001) The New Meaning of Educational Change. (3rd edition.p 230,194). Tirana: Edualba.

Gjokuta, M. (2009) Teaching of Albanian language, (p.266) Tirana:SHBLU.

MASH. (2004 - 2015) National Strategy of Education

Kazaz, N.(2002). Work with combined classes in primary school -SHU Scientific Bulletin.(Series didactic studies. Year XXXII 52. P.6776) (52), Shkodra.

AEDP. (1999). Teaching method. (Group of authors). Tirana

Beci, B. (1993). For a contemporary conception of native language learning in school - Our Language. (ASH. IGjL. No. 1-4. p.101-105) Tirana

Gjokuta, M. (2001). Problems of today's Albanian language teaching in schools- Curriculum and schools. Albanian language \& literature readings. (1.ISP Edition. P. 19-46). Tirana.

Gjokuta, M. (2001). Experience of teaching the native language- Curriculum and schools. Albanian language \& literature readings. (1.ISP Edition. P. 112-134). Tirana.

Gjokuta, M. (2002). Common student writings- Curriculum and schools. Albanian language \& literature readings. (2 . ISP Edition. P. 3756). Tirana.

Gjokuta, M. (2002). Albanian pedagogical thinking for teaching the Albanian language at school- Curriculum and schools. Albanian 
language \& literature readings. (3. ISP Edition. P. 68-92). Tirana.

Gjokuta, M.; Kazaz, N. (2003). The trend of today's Albanian language- Albanian Studies 12. (SHU Edition "Luigj Gurakuqi", Faculty of Social Sciences. P.184-193). Shkodra.

Gjokuta, M. (2003). Status and prospects of development of the Albanian language course in elementary school" - "Curriculum and schools ," Albanian language \& literature readings. (5 . ISP Edition. P. 62-82). Tirana.

Gjokuta, M. (May 28, 1994, June 4, 1994) Methods of learning about literacy. Teacher (p. 4) Tirana.

WB. (June 2013) Overview of the partnership program

\section{Appendix}

Data of Table 1 illustrated in a graphic slides:

Figure 1:

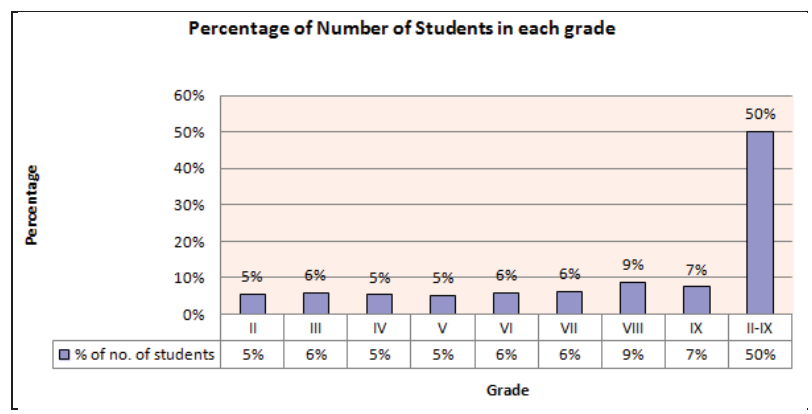

Figure 2:

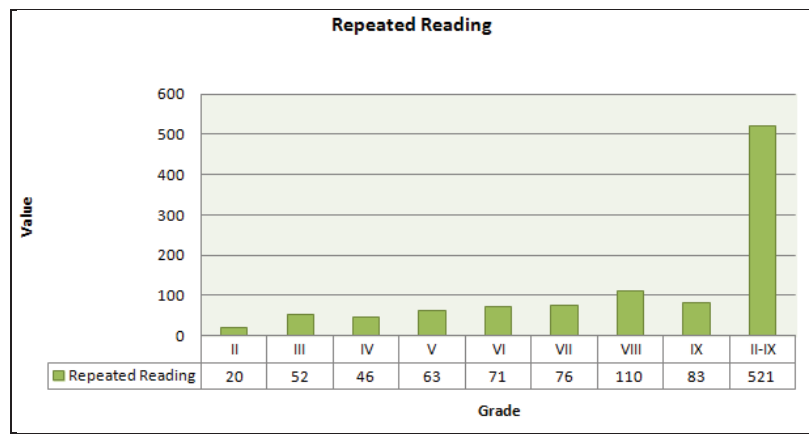

Figure 3:

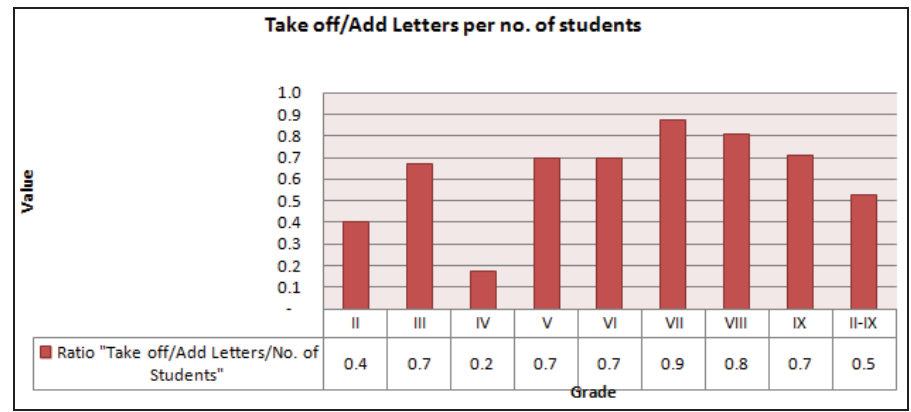




\section{Figure 4:}

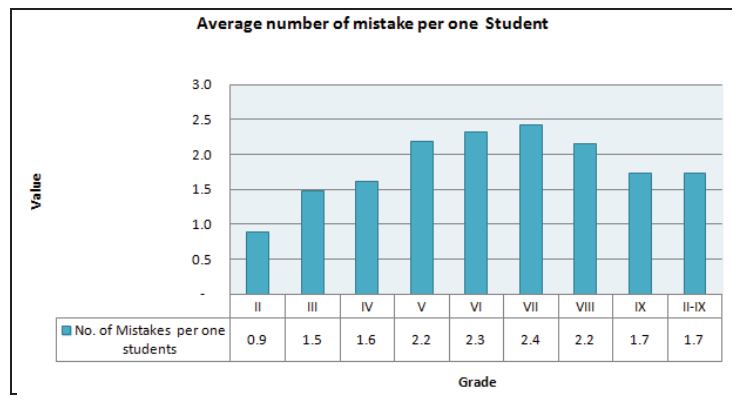

Figure 5:

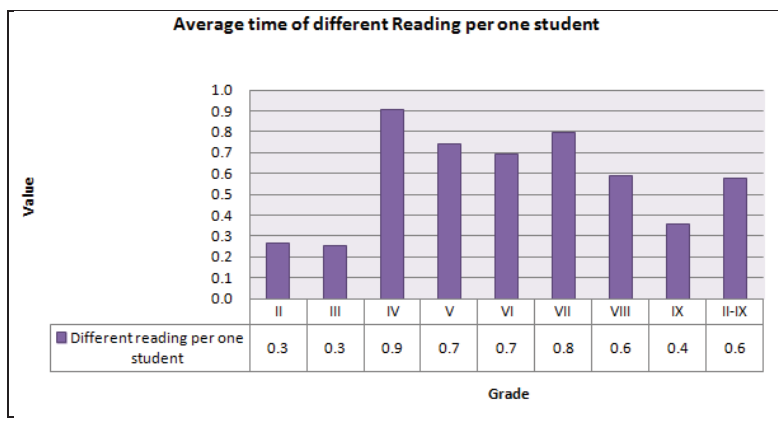

Figure 6:

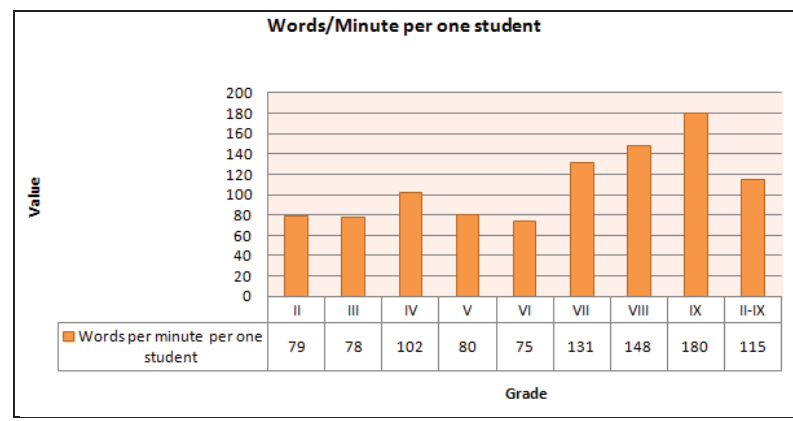

Figure 7:

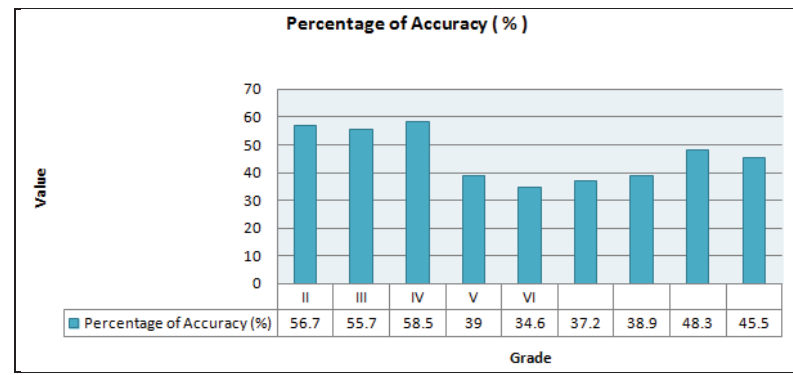


Figure 8:

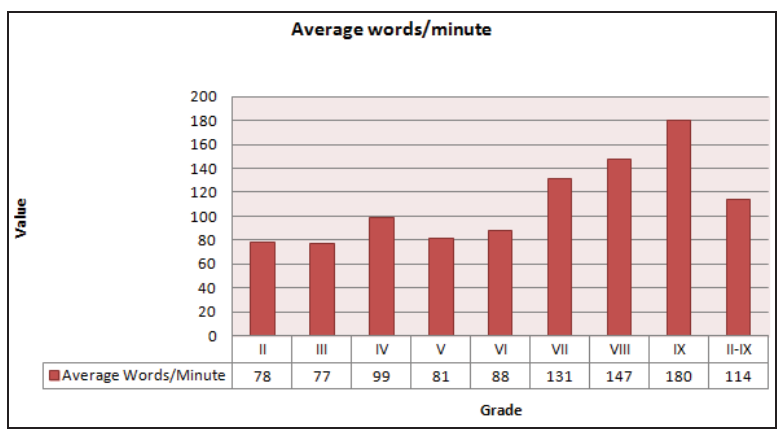

\section{Annexes}

\section{Table of measuring speed in reading}

Evidence for the quality and accuracy in reading (M Gjokuta, Teaching of Albanian, Tirana 2009)

Words per minute Tirana, on Time to read the text $60 \mathrm{~s}$ (1min)

\begin{tabular}{|l|l|l|l|l|l|l|}
\hline No & Name & Take off/Add letters & Reeated Reading & Different REading & Words per minute & Reading time 1min \\
\hline 1 & & & & & & \\
\hline 2 & & & & & & \\
\hline 3 & & & & & & \\
\hline
\end{tabular}

\section{Teacher Survey $\underline{\text { Content }}$}

\begin{tabular}{|l|l|l|l|l|l|}
\hline Problems & None & Little & Good & Moderate & Highly \\
\hline The principle of integration in your subject makes a difference for you? & & & & & \\
\hline The techniques and teaching methods enable subject integration? & & & & & \\
\hline $\begin{array}{l}\text { Does the learning process, with its focus on the student- enables an active and } \\
\text { productive reading process? }\end{array}$ & & & & & \\
\hline Focused reading restricts the use of different teaching methods? & & & & & \\
\hline $\begin{array}{l}\text { Is the Quality of reading declining passing from one grade to the other in both } \\
\text { cycles? }\end{array}$ & & & & \\
\hline $\begin{array}{l}\text { How much does the focused reading affect the consolidation of knowledge } \\
\text { between different subjects? }\end{array}$ & & & & & \\
\hline How adversely does Internet use affect the reading and writing process? & & & & & \\
\hline $\begin{array}{l}\text { What is the percentage of teachers requiring that materials obtained from the } \\
\text { Internet be turned in written synopsis? }\end{array}$ & & & & & \\
\hline $\begin{array}{l}\text { With the reading process should work only elementary teachers or teachers in } \\
\text { both cycles? }\end{array}$ & & & & & \\
\hline
\end{tabular}

- Do you have something to add from your experiences? 